\title{
Lessons from Discarded Computer Architectures
}

\author{
Andrew E. Fluck \\ University of Tasmania \\ Locked Bag 1307, Launceston, Tasmania, 7250, Australia \\ Andrew.Fluck@utas.edu.au
}

\begin{abstract}
The BBC microcomputer was one of several nationally produced which were superseded by the International Business Machines (IBM) Personal Computer (PC). This reflected the results of both an international market competition and rivalry between different US processor manufacturers. Along with the hardware, valuable software and supporting educational ideologies were discarded. As we make choices about technological innovation, to what degree are we selecting potential efficacy or responding to marketing hype?
\end{abstract}

Keywords: BBC microcomputer, IBM Personal Computer, Apple II, computer hardware, operating systems.

\section{Introduction}

The BBC microcomputer was an 8-bit machine based on the Motorola 6502 processor. It made a huge impact in British schools, putting predecessors into the shade of its colour graphics. Its successor, the Archimedes was almost as successful, but ran into the juggernaut of the IBM PC - and the rest is history. Almost.

\section{The BBC Microcomputer - A Withered Branch}

In 1979-80 the British Broadcasting Company (BBC) started the BBC Computer Literacy Project and put out a tender for a microcomputer to accompany the television series The Computer Programme. Acorn was a firm started by two former Sinclair employees, marketing director Chris Curry and researcher Hermann Hauser. Their firm won the tender in April 1981 and released the BBC Microcomputer later that year. The large keyboard unit connected to a conventional television, which became the screen for the computer. Based on the 8-bit Motorola 6502 processor, the initial model had 16k bytes of RAM, and cost GBP 299. Backup storage was initially to cassette tape, with floppy disks (51/4") coming later. Notably the computer had many interfaces, including networking (CDMA econet), a serial RS-423 port, analog input (for joysticks etc.), parallel input/output user port Centronix printer port, RGB, composite video and TV outputs. The operating system was in read-only memory (ROM), and this contained a BASIC interpreter. Additional language ROMS could be installed to give extra functionality. One such language was Micro PROLOG which was 
released by Acornsoft in 1985. This was a declarative language, very different from the sequential algorithmic languages familiar to most programmers of the time. To overcome this novelty, a Man in the Street Interface (MITSI) was written by Jonathan Briggs at Imperial College London, and made popular by Jon Nichol from the School of Education, University of Exeter [1,2]. Jackie Dean worked in Western Australia, providing an antipodean link.

The BBC micro was put on sale, and additionally the British government Department of Trade and Industry arranged to place one into every school, since the advent of microelectronics was expected to have a major impact on commerce and work. The Department of Education set up a series of national advisory units which continue today as Becta (formerly the British Educational Communications and Technology Agency). Production was discontinued in 1994 by which date over one million BBC Micros had been sold in the UK and Europe [3].

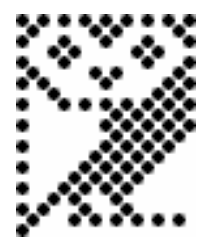

Fig. 1. Logo of the BBC Computer Literacy Project

John Coll, an electronics teacher from Oundle School was hired to write the user manual for the BBC micro [4] and also appeared in related television programs. This author recalls sitting in his office to discuss a new programming project when one of the operating system programmers rushed in. He had recoded some graphics routines and saved 10 bytes of space in the ROM. This would make possible the inclusion of an additional function!

The BBC micro was very popular in British schools. As part of the government support for schools IBM sponsored a project for the Redbridge SEMERC (Special Education Microelectronics Resource Centre) by M-Tec computer services (UK) to create a card for the IBM Personal Computer which would replicate some of the interface ports on the BBC micro. Devices such as the concept keyboard and various robotic turtles (controlled by variants of the LOGO language) were so popular, this sought to ease the conversion of educational software onto the more dominant platform. The SNIC card (special needs interface card) had a short life.

Acorn went on to produce successors to the BBC micro: the Archimedes and then the RISC-PC in 1994. However, the company was broken up in 1998, and Castle Technology acquired the rights to market and produce this later machine [5]. The RISC-PC was supplanted by the Iyonix PC in 2003, but even this was discontinued in 2008 [6].

One thing that did emerge from these discarded Acorn computer architectures was the idea of a RISC (reduced instruction set computer). The first such processor was incorporated in Acorn's 32-bit computer in 1985 - the Archimedes [7]. A new company, Advanced RISC Machines (ARM) was formed in 1990, and became very successful in designing this new kind of chip. ARM processors had very low power 
consumption, and were ideal for mobile application where battery life matters. Leading into 2007 they were used in over $98 \%$ of the world's billion mobile phones [8].

A person who links the withered branch of the BBC computer to the highly successful ARM processor tree is Tudor Brown. He studied Electrical Engineering at Cambridge University, and was awarded an M.A. in Electrical Sciences. He was enticed back to the city again in 1983 to join Acorn Computers, where he worked on the ARM R\&D program as Principal Engineer. When ARM spun out from Acorn as a joint venture with Apple, he became Engineering Director and then Chief Technical Officer from 1993 [27] In October 2000 he was appointed Executive Vice President, Global Development and in October 2001, joined the board of ARM as Chief Operating Officer. He became President in 2008 with responsibility for developing highlevel relationships with industry partners and governmental agencies and for regional development [9].

This withered branch of computer architecture contains the seeds of a comparison between marketing success and intellectual striving. It embraces the success of algorithmic thinking based upon uni-processor machines and a failure to make progress with multi-processor computers. To explain the next withered branch, we need to give an overview of the instruction sets associated with particular processor families.

\section{Links between Processor Families and Operating Systems}

An operating system is a collection of programming codes designed to provide a consistent interface between hardware and the software applications run by the computer user. In this sense, an operating system can run on any hardware to which it has been adapted, and the software application will run as expected. When an operating system runs consistently on more than one processor, it must be coded using a different instruction set for each. The instruction set consists of all the various instructions that the processor can execute.

It can be quite difficult to create and maintain an operating system, and this causes some inertia in the versioning process to cope with different processors. Therefore while it is not strictly necessary for a particular operating system to be associated with a specific processor development family, in the main this has been the case.

The two most significant such associations have been Windows with Intel x86 line processors and Apple's Macintosh operating system with Motorola 6xxx line of processors and others. The Microsoft Disk Operating System (MS-DOS) with its successive versions of Microsoft Windows has been developed to run on 16, 32bit and 64bit processors from Intel; currently the Atom and Core-i7. These have been developed from the original 8086 (16bits, 1978), through the 80486 and Pentium (in 1993) versions [10].

The Apple line of succession began in 1977 with the Apple II using the Motorola 6502 processor which ran operating systems such as CP/M [11]. The Apple II was the first true "personal computer" which was factory built, inexpensive and easy to learn and use. Provided with the most extensive set of software and low cost floppy disks, the Apple II was also the first personal computer capable of color graphics and easy modem operation. Development of the Visicalc spreadsheet program created a business tool that made adoption of Apple II a regular part of business [12]. The processor 
development series moved to the Motorola 68000 and the Apple Macintosh line of computers. These ran a new operating system with some routines in Read Only Memory (ROM) for speed. This operating system was called 'System' in 1984, but gradually became called MacOS. It incorporated elements from FreeBSD's and NetBSD's implementation of Unix from 1996 [13].

The processors used by Apple changed from the Motorola 68040 series to PowerPC chips (Motorola and IBM) and then to Intel x86 chips from 2007.

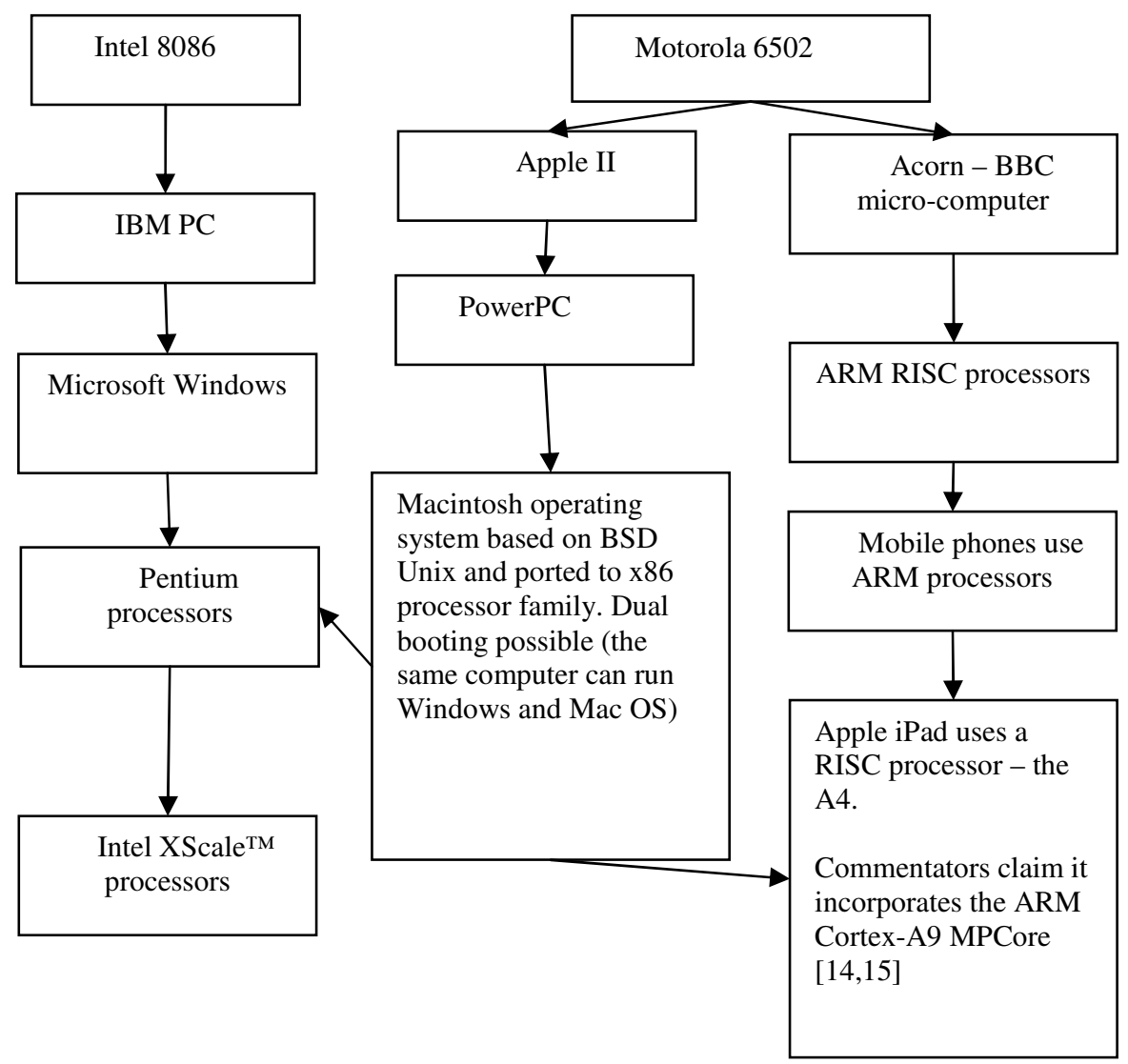

Fig. 2. Development pathways for two dominant personal computer families

It should be noted that all these processor families were von Neumann computers with a single processor. This architecture has a single memory store which holds instruction codes and data. Programs run sequentially, and therefore an algorithmic approach is highly congruent with such machines. Fortunately many problems can be solved by such methods, and the high speed ( $3 \mathrm{GHz}$ is not uncommon) of processor operation supports a wide range of useful functions.

An alternative was offered by the Transputer from Inmos [16] from 1983 [17]. Inmos Limited was a British semiconductor company, founded by Iann Barron, based in 
Bristol and incorporated in November 1978. Inmos ceased trading, and many staff moved to SGS-Thomson (now STMicroelectronics) in April 1989 and was fully absorbed by 1994 [18].

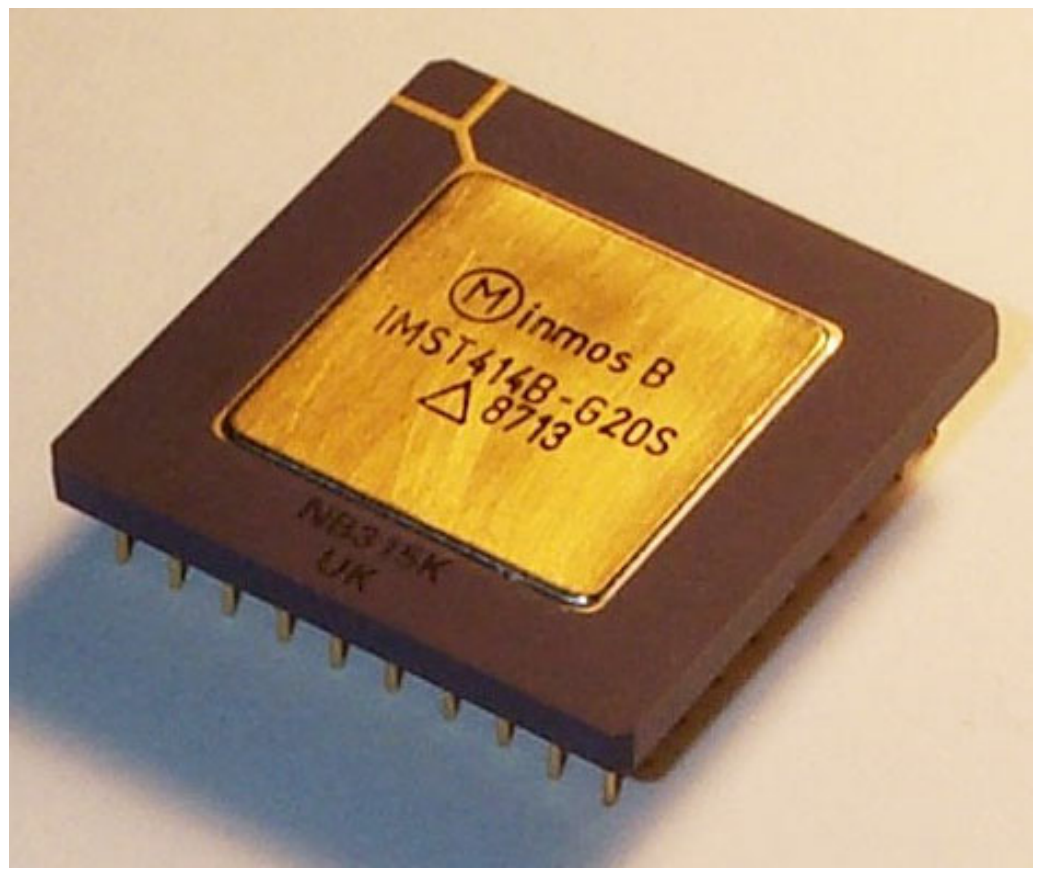

Fig. 3. A Transputer chip [19]

\section{Alternatives to the Von Neuman Design - Triumph of Algorithm over Heuristic}

Each Inmos Transputer chip contained a processor, RAM storage and communication ports. The chips were designed to be wired together in arrays. Whereas most single processor computers are limited to handling problems using sequential steps, parallel hardware could solve problems faster by undertaking multiple computations simultaneously.

The question is, how can programmed solutions be stated in this new form? If a sequential language is used (such as the old FORTRAN code), a translator must identify and exploit steps that can run simultaneously [20]. If a non-sequential language is used instead, a different kind of approach is needed.

Some problems, such as weather forecasting or industrial product design, use mathematical methods such as finite element mesh analysis [21], which map very well onto processor arrays. Of course, using very high speed networks, the computer array can be established as a virtual machine, and therefore multiple PCs can be used for similar purposes using control software such as Beowulf clusters [22]. Explorations into distributed processing architectures still continue [23]. 
The general application of parallel processor architectures depends upon theoretical advances that can establish the importance of parallel universality [24].

Others have investigated parallel processor arrays. These include Intel, whose iWARP product was evaluated for use in the international space station [25] where it gave computational speed increases of an order of magnitude over a single processor equivalent. Product development led to a commercial supercomputer product, the Intel Paragon XP/S [26].

Despite these advances, parallel computing has not achieved the hopes of the fifth generation computing project, and applications appear to remain restricted to specialised (but important) situations. Interest has moved to quantum computing, where the superimposition of energy states are expected to be processed using optical methods to solve problems extremely quickly.

\section{Conclusion}

There appear to be four lessons to be learned from this story of discarded computer architectures. Firstly, the BBC microcomputer was quickly supplanted by the openarchitecture IBM PC and the closed architecture Apple Macintosh. However, the RISC processor designed for the BBC microcomputer's successor has been widely adopted because of its very low power consumption. In a world faced by climate challenge and a huge growth in the use of mobile computing devices, this has been a winning strategy.

The second lesson can be drawn from the way personal computer operating systems have been largely linked to processor families. Most of the main lines of growth have been limited to von Neuman uni-processor architectures. Even the development of quad or more core processors are still just variants of this sequential flow machine, albeit allowing a few more threads to access different parts of memory simultaneously. The lesson of how to break away from this design template has yet to be learned.

The third lesson relates to the Transputer and ways in which these chips could be wired in arrays. Even declarative languages such as Prolog were not ported successfully to this architecture in such a way to facilitate problem solving which became mainstream. We appear to lack an understanding of how to implement solutions using these kinds of techniques.

Finally, our hopes of leapfrogging this difficulty rest with novel computing techniques such as quantum or biological constructs. It remains to be seen how successful these will be - and they may need to take heed of the other three lessons to achieve their goals.

\section{References}

1. Nichol, J., Briggs, J., Dean, J.: PROLOG in education. Educational Review 39(2), 137-146 (1987)

2. Nichol, J., Dean, J., Briggs, J.: Teachers encounter PROLOG. Journal of Computer Assisted Learning 2(2), 74-82 (1986)

3. Hornby, T.: Acorn and the BBC Micro: From Education to Obscurity (2007), http: / / lowendmac.com/orchard/07/0228.html (February 12, 2010) 
4. Coll, J.: The BBC microcomputer: User Guide. British Broadcasting Corporation, London (1982)

5. Williams, C.: Castle bids farewell to RiscPC: Somebody call the fat lady. Drobe launchpad: the archives (2003),

http: / /www. drobe.co.uk/riscos/artifact869.html (February 14, 2010)

6. Lillingston, J.: Iyonix Ltd. (2008), http://wWw.drobe.co.uk/extra/PR07IYONIXproductiontocease. txt (February 14, 2010)

7. ARM Ltd. Company Profile: Milestones (2009), http://www.arm.com/about/company-profile/milestones.php (February 14, 2010)

8. Krazit, T.: ARMed for the living room. CNET News (2006), http: //news. cnet.com/ARMed-for-the-living-room/2100-1006_36056729.html (February 14, 2010)

9. ARM Ltd. Corporate Governance: Board of Directors (2010), http: / / ir.arm. com/phoenix. zhtml ?c=197211\&p=irol-govboard (February 14, 2010)

10. Intel Corporate Timeline (2009), http: / /www. intel.com/museum/corporatetimeline/ (February 14, 2010)

11. Petersen, M.: Review: Premium Softcard IIe. InfoWorld (InfoWorld Media Group) 6(6), 64 (1984)

12. Veit, S.: PC history: Pre-IBM PC Computers (2002), http: / / www .pc-history.org/ (February 12, 2010)

13. Markoff, J.: Why Apple Sees Next as a Match Made in Heaven, The New York Times, p. D1 (December 23, 1996) (newspaper),

http : / / query . nytimes. com/gst / fullpage.html ?res=9F06E1D71331F 930A15751C1A960958260 (February 12, 2010)

14. Richards, D.: The new Apple iPad processor the media forgot. Smarthouse: The lifestyle technology guide (February 2, 2010),

http: / /www.smarthouse.com.au/Home_Office/Industry/G6P4K6R7?p age $=2$ (February 15, 2010)

15. Wilson, R.: Apple iPad processor strategy exposed. Computer Weekly (January 28, 2010), http: / /www. computerweekly.com/Articles /2010/01/28/240104/App le-iPad-processor-strategy-exposed.htm (February 14, 2010)

16. Hey, A.J.G.: Supercomputing with transputers-past, present and future. In: Proceedings of the 4th International Conference on Supercomputing (1990), http: / /delivery.acm.org/10.1145/260000/255192/p479hey $\cdot$ pdf ? key $1=255192 \& k e y 2=0206885621 \& \mathrm{col} 1=$ GUIDE\&dl=GUIDE\&CFID $=75789577 \&$ CFTOKEN $=52277307$

17. Arabnia, H.R.: The Transputer family of products and their applications in building a high performance computer. In: Belzer, J., Holzman., A.G., Kent, A. (eds.) Encyclopedia of Computer Science and Technology, vol. 39, p. 283 (1998)

18. Charles, D.R., Benneworth, P.S.: Clustering and economic complexity - regional clusters of the ICT sector in the UK. Paper Presented to the OECD Cluster Group Workshop, Utrecht (2000), http: / /www. oecd.org/dataoecd/34/42/2099353.pdf (February 14, 2010)

19. Letdorf: A Transputer chip - Wikipedia (2006)

20. Hiranandani, S., Kennedy, K., Tseng, C.: Compiling FORTRAN D for MIMD distributedmemory machines. Communications of the ACM 35, 66-80 (1992) 
21. Widas, P.: Introduction to Finite Element Analysis. Virginia Tech Material Science and Engineering (1997),

http://www.sv.vt.edu/classes/MSE2094_NoteBook/97ClassProj/nu $\mathrm{m} /$ widas/history.html (February 13, 2010)

22. Beowulf.org, What makes a cluster a Beowulf (2007), http: / / www . beowulf . org/overview/index.html (February 15, 2010)

23. Kim, H., Smith, J.E.: An Instruction Set and Microarchitecture for Instruction Level Distributed Processing, isca In: 29th Annual International Symposium on Computer Architecture (ISCA 2002), p. 0071 (2002)

24. Valiant, L.G.: Bulk-Synchrony: A Bridging Model for Parallel Computation. In: Proceedings of DMCCS, Charleston (1990)

25. Hine, B., Fong, T.W.: Evaluation of the Intel iWarp Parallel Processor for Space Flight Applications. In: AIAA Aerospace Design Conference (February 1993), http://www.ri.cmu.edu/pub_files/pub4/hine_butler_1993_1/hine butler_1993_1.pdf (February 13, 2010)

26. Smirni, E., Reed, D.A.: Workload characterization of input/output intensive parallel applications. In: Marie, R., Plateau, B., Calzarossa, M.C., Rubino, G.J. (eds.) TOOLS 1997. LNCS, vol. 1245, pp. 169-180. Springer, Heidelberg (1997)

27. Centre for Entrepreneurial Learning (no date) The Cambridge Entrepreneurs: Tudor Brown, http://www.cfel.jbs.cam.ac.uk/resources/cambridgeents_brown. html (February 12, 2010) 